\title{
Increased level of circulating cell-free mitochondrial DNA due to a single bout of strenuous physical exercise
}

\author{
Lars Ohlsson $^{1}$ (D) Anna Hall ${ }^{2} \cdot$ Hanne Lindahl ${ }^{3} \cdot$ Ravi Danielsson $^{1} \cdot$ Anna Gustafsson $^{1} \cdot$ Eva Lavant $^{1}$. \\ Lennart Ljunggren ${ }^{1}$
}

Received: 10 October 2019 / Accepted: 17 February 2020 / Published online: 22 February 2020

(c) The Author(s) 2020

\begin{abstract}
Purpose Physical exercise is reported to affect the immune response in various ways. Thus, the levels of pro-inflammatory cytokines as well as the abundance of circulating leukocytes are changed. In this study, the occurence of circulating cell-free mitochondrial DNA (cfmtDNA) and nuclear DNA (nDNA) was investigated in connection with a single bout of strenuous physical exercise.

Methods Healthy volunteers performed a controlled ergo-spirometry cycle test and venous blood samples were taken at different time-points to analyze the concentration of blood components before, during and after the test. The number of circulating leukocytes was measured, as well as secretion of the soluble urokinase activator receptor (suPAR).

Results Cf-mtDNA significantly increased during exercise, compared to baseline values and after 30 and 90 min of rest. Circulating leukocytes increased during exercise, but returned to baseline levels afterwards. Surface expression of the urokinase plasminogen activating receptor (UPAR) on neutrophils decreased significantly during exercise. The concentration of suPAR tended to increase during exercise but only significantly after 90 min of rest.

Conclusion Increased concentration of cf-mtDNA indicates that cell damage takes place during high intensity training. Hypoxia and tissue damage are likely causes of cf-mtDNA from muscle cells. The levels of cf-mtDNA remain high during the initial rest, due to the decreasing numbers of leukocytes normally clearing the plasma from cf-mtDNA. The increased levels of suPAR further emphasize that strenuous physical exercise causes a reaction similar to inflammation. Further studies are needed to detect the source of increased cf-mtDNA and the corresponding increase of suPAR liberation.
\end{abstract}

Keywords Cell-free mitochondrial DNA $\cdot$ Exercise $\cdot$ Inflammatory response $\cdot$ Leukocytes $\cdot$ Soluble urokinase plasminogen activator receptor

\section{Abbreviations}

ATP

$\beta 2 \mathrm{M}$

BSA

cf-mtNDA

cf-nDNA

Adenosine-tri-phosphate

Beta-2 microglobulin

Bovine serum albumin

Cell-free mitochondrial DNA

Cell-free nuclear DNA

Communicated by Fabio Fischetti.

Lars Ohlsson

lars.ohlsson@mau.se

1 Department of Biomedical Science, Malmö University, Malmö, Sweden

2 Department of Clinical Chemistry, SUS, Region Skane, Malmö, Sweden

3 Department of Clinical Pathology, SUS, Region Skane, Malmö, Sweden
DAMP Danger-associated molecular pattern

EDTA Ethylenediaminetetraacetic acid

IFN- $\gamma \quad$ Interferon-gamma

IL-1 $\beta \quad$ Interleukin 1-beta

IL-6 Interleukin-6

LPS Lipopolysaccharide

MDD Major depressive disorder

MFI Mean fluorescent intensity

MMP Matrix metalloproteinase

mtDNA Mitochondrial DNA

ND1 NADH dehydrogenase 1

ND2 NADH dehydrogenase 2

NET Neutrophil extracellular traps

PBS Phosphate-buffered saline

qPCR Quantitative polymerase chain reaction

SIRS Systemic inflammatory response syndrome 


$\begin{array}{ll}\text { suPAR } & \begin{array}{l}\text { Soluble urokinase-type plasminogen activa- } \\ \text { tor receptor }\end{array} \\ \text { TLR } & \text { Toll-like receptor } \\ \text { TNF- } \alpha & \text { Tumor necrosis factor-alpha } \\ \text { uPAR } & \text { Urokinase-type plasminogen activator } \\ & \text { receptor }\end{array}$

\section{Introduction}

The effect of strenuous physical exercise on the immune system has been studied during the last years. Both acute and chronic training have been investigated, often in connection with various disease syndromes, such as depression or multiple sclerosis (Hallberg et al. 2010; Mikkelsen et al. 2013; Suchanek et al. 2010; Zwetsloot et al. 2014). A single bout of physical activity leads to both cellular and humoral immune responses similar to those caused by infection, sepsis and trauma (Steensberg et al. 2000). The plasma concentration of the pro-inflammatory cytokines (e.g. TNF- $\alpha$, IL-1 $1 \beta$, IL-6 and IFN- $\gamma$ ) as well as acute-phase proteins increase (Boettger et al. 2010; Castellano et al. 2008). However, the degree of immune activation is reported to decrease in persons that perform regular training (Simpson et al. 2015).

Mitochondria are organelles responsible for the synthesis of ATP (Johannsen and Ravussin 2009; Scheffler 2001) and are also responsible for the generation of signaling molecules involved in apoptosis and necrosis (Johannsen and Ravussin 2009). The number of mitochondria per cell depends on its energy requirement, and e.g. muscle cells are equipped with many mitochondria to perform their regular work (Wust et al. 2018). Regular exercise has been shown to increase the number of mitochondria in muscle cells, resulting in an increased ability to synthesize ATP. In case of cellular damage, endogenous cellular substances normally not exposed to the immune system, act as danger-associated molecular patterns (DAMPs), as they are released into the circulation. These molecules are then recognized by different pattern recognition receptors, such as Toll-like receptors (TLRs), on immune cells causing a signaling cascade leading to excretion of antimicrobial substances and pro-inflammatory substances (Zhang et al. 2010a, b). Mitochondrial DNA (mtDNA), released into circulation from mitochondria under stress, has been reported to act as a DAMP, mimicking an ongoing immune-activation, mediating a pro-inflammatory response (Bhagirath et al. 2015; Chiu et al. 2003; Yu 2012). Systemic inflammatory response syndrome (SIRS) is a condition when several pro-inflammatory mediators, due to cellular damage caused by tissue-damage, trauma or hypoxia are released into the blood. Since heavy physical exercise, due to muscle damage, necrosis and oxygen deprivation has been shown to result in immune-activation resembling trauma and sepsis, the contribution of mitochondrial function has to be taken into account. Studies of trauma have revealed that inflammation, neutrophil activation and organ injury can be mediated by cell free mtDNA (cf-mtDNA) activating neutrophils via TLR-9, normally binding bacterial DNA (Zhang et al. 2010a, b).

Another useful biomarker for immune activation is the soluble urokinase plasminogen activating receptor (suPAR) (Thuno et al. 2009) however, only a few studies can be found describing the effect from intense physical activity on suPAR (Gustafsson et al. 2017; Sanchis-Gomar et al. 2013). suPAR is the soluble fragment of the multiligand receptor urokinase plasminogen activating receptor (UPAR or CD87). uPAR, expressed on several cell types, including neutrophils, monocytes, and endothelia cells, is involved in both proteolysis, cell-migration, angiogenesis, and inflammation. During the last decades, several studies have been investigating the possible use of suPAR as a biological marker of inflammation, organ damage, and severity of the disease, showing positive correlations between increased suPAR concentrations in both blood, urine and cerebrospinal fluid (Enocsson et al. 2015; Thuno et al. 2009).

During infection and inflammation, as well as during physical exercise, an increased number of circulating leukocytes is observed (Pedersen and Hoffman-Goetz 2000). Leukocytosis during physical exercise is caused by de-margination of leukocytes from the marginal pool caused by increased heart rate and blood flow, as well as by increased concentrations of epinephrine and cortisol (Sanchis-Gomar and Lippi 2014). Neutrophils, dendritic cells and lymphocytes have shown to increase during exercise (Pedersen and Hoffman-Goetz 2000; Suchanek et al. 2010). After exercise, the lymphocytes decrease below base-line but the levels of neutrophils remain increased (Pedersen and Hoffman-Goetz, 2000; Simpson et al. 2015).

The aim of this study was to investigate if a bout of strenuous physical exercise leads to changed levels of circulating cf-mtDNA in plasma and to examine if a correlation between cf-mtDNA levels, suPAR, and total leukocytes could be established. Moreover, a possible correlation of membranebound uPAR (CD87) and free suPAR was investigated.

\section{Materials and methods}

Healthy volunteers $(n=8)$ performed a controlled ergospirometry cycle test and venous blood samples were taken at different time-points to analyze the concentration of blood components before, during and after the test. The subjects were requested not to eat or drink $2 \mathrm{~h}$ before the test, nor drink alcoholic beverages during the day before the test. 


\section{Subjects}

Eight non-smoking volunteers [four female and four male, aged 20-61 $(38.6 \pm 14.4)$ ], with no known history of heart- or lung disease and a normal BMI participated in the cycle test. The actual fitness of the subjects was not known. Ethical approval for the implementation of the study was obtained from the Ethical Council of the Faculty of Health and Society, Malmö University (Ref: HS60-2015/306: 2) and the study was performed, according to the Helsinki declaration (2013). All participants gave their written consent.

\section{Ergospirometry, samples collection and handling}

When the test started the resistance for female participants was set to $30 \mathrm{~W}$ on the Ergometer (Monarch Ergomedic 939E, Monark Exercise AB in Vansbro, Sweden) and was subsequently gradually allowed to increase by $10 \mathrm{~W} / \mathrm{min}$. Male participants started at $50 \mathrm{~W}$, gradually increased by $15 \mathrm{~W} / \mathrm{min}$. Throughout the test, the volunteers were encouraged to keep a steady pace on the pedals (about 60-65 revolutions/min). Blood samples were taken via a peripheral venous catheter (BD Venflon ${ }^{\mathrm{TM}}$ Pro Safety and BD Connecta $^{\mathrm{TM}}$, Becton Dickinson, Helsingborg, Sweden) at five specific time points (on arrival after $15 \mathrm{~min}$ of rest (zero/0sample), at submaximal- and maximum load, and at 30 and 90 min after the test). After each sampling, the catheter was flushed with $5 \mathrm{~mL}$ of physiological saline. Time of sampling at the maximum load took place when the subjects reached exhaustion, indicating that they could not cycle any further. All blood samples were taken while the subjects were sitting, either at the bike or in an upright position. Sub-maximal load was considered to be reached either when the subject had cycled for six minutes at an increasing resistance or when a heart rate of $125 \pm 5$ beats/min was reached. Blood samples were collected in EDTA vacutainers and placed on ice or at room temperature depending on further analysis. Plasma from blood samples was prepared by centrifugation within one hour of sampling at $4{ }^{\circ} \mathrm{C}$ at $2000 \times g$ for $10 \mathrm{~min}$, and stored at $-80^{\circ} \mathrm{C}$. Correction of plasma volume changes during the test was performed using blood hemoglobin values (Alis et al. 2015).

\section{Hematology analysis}

Determination of leukocyte concentration, differential counts, and hemoglobin concentration was performed on blood from the sampling tube which had been stored at room temperature (between one and five hours). The blood was mixed well and then analyzed with HemoCue ${ }^{\circledR}$ WBC DIFF and HemoCue Hb $201+$ instruments (HemoCue AB, Ängelholm, Sweden), following the manufacturer's instructions.

\section{Flow cytometric analysis}

Within three hours from sampling, $100 \mu \mathrm{L}$ of blood was transferred into $1.5 \mathrm{~mL}$ tubes. Labeling of cells was made with the following antibodies from BD Biosciences (Stockholm, Sweden): APC mouse anti-human CD11b, PE mouse anti-human CD87, APC mouse anti-human CD14 and APC mouse-anti human CD3. Corresponding isotype antibodies were used as negative controls. The tubes were incubated at room temperature for $30 \mathrm{~min}$ and erythrocytes were lysed using $1 \mathrm{~mL}$ FACS Lysing Solution (BD Biosciences, Stockholm, Sweden) for $30 \mathrm{~s}$ at room temperature. The cells were then washed with $1 \mathrm{~mL}$ PBS (Life Technologies Europe BV, Stockholm, Sweden) with 1\% BSA (Sigma-Aldrich Sweden AB, Stockholm, Sweden). The tubes were centrifuged at $1000 \times g$ for five minutes and the supernatant was discarded and the washing procedure was repeated once more. Finally, the cells were resuspended in $0.5 \mathrm{~mL}$ CellFIX (BD Biosciences, Stockholm, Sweden) and protected from light before flow cytometric analysis.

The flow cytometric analysis was performed on an Accuri C6 (BD Biosciences, Stockholm, Sweden) with the associated software CFlow Plus (BD Biosciences, Stockholm, Sweden). For each sample, data were collected from 25,000 cells in the total leukocyte gate.

\section{Analysis of suPAR}

Plasma (EDTA) suPAR concentrations were analyzed using a commercially available enzyme immunoassay (suPARnosticTM, Virogates, Copenhagen, Denmark), according to the manufacturer's instructions. The assay detects all circulating suPAR, including intact and cleaved forms of the receptor.

Samples were analyzed in duplicates and the mean was used for statistical analysis. The detection limit for suPAR was $0.1 \mathrm{ng} / \mathrm{mL}$ according to the manufacturer.

\section{Measurement of circulating cell-free mitochondrial and nuclear DNA}

The isolation and quantification of cf-mtDNA/nuclear DNA (nDNA) in plasma samples has previously been described (Lindqvist et al. 2016). Briefly, the thawed plasma samples were centrifuged for $10 \mathrm{~min}$ at $10,000 \times g$ and DNA was isolated from the top $200 \mu \mathrm{l}$ using the QIAmp 96 DNA Blood Kit (Qiagen, Valencia, CA, USA) according to the manufacturer's instruction using the blood and body-fluid protocol. The isolated DNA was eluted in $200 \mu$ Tris-EDTA-buffer (TE-buffer) and quantified with a Nanodrop (ND-1000 
Spectrophotometer v 3.7.1, Waltham, MA, USA) using spectrophotometric analysis at $260 / 280 \mathrm{~nm}$. The quantitative analysis of cf-mtDNA and nDNA (NADH dehydrogenase, ND2 and beta-2-microglobulin, $(\beta 2 \mathrm{M})$ ) was performed using quantitative real-time polymerase chain reaction (qPCR). The PCR reactions were carried out using SYBR Green Technology (Thermo Fisher Scientific, Waltham, MA, USA). Each $20 \mu \mathrm{l}$ reaction contained $5 \mu \mathrm{l}$ of template, $1 \mu \mathrm{L}$ of each primer $(10 \mu \mathrm{M}), 10 \mu \mathrm{L}$ SYBR MIX $(2 \times$ Sensifast, Bioline, London, UK) and $3 \mu \mathrm{L}$ of nuclease-free water. Each reaction was run in triplicate on a LC480 LightCycler from Roche, Mannheim, Germany) using the following program: Initial denaturation at $95{ }^{\circ} \mathrm{C}$ for $10 \mathrm{~min}, 45$ cycles consisting of $95^{\circ} \mathrm{C}$ for $10 \mathrm{~s}, 65^{\circ} \mathrm{C}$ for $10 \mathrm{~s}$ and $72{ }^{\circ} \mathrm{C}$ for $11 \mathrm{~s}$. The program was terminated with a melting curve analysis measuring fluorescence continuously from 60 to $97^{\circ} \mathrm{C}$.

Serial dilutions (dilution factor 10) in eight steps of the purified PCR products, starting with $56 \mathrm{pg} / \mu \mathrm{L}$ (ND2) or $4 \mathrm{~L} \mathrm{pg} / \mu \mathrm{l}(\beta 2 \mathrm{M})$ were used to create standard curves. The obtained crossing-point values from the unknown samples were compared with the standard curve, and the corresponding number of mitochondrial or nuclear units was calculated. Calculations were carried out as described in Lindquist et al. (2016).

\section{Statistics}

Data are presented as mean values $\pm \mathrm{SD}$. Differences at various time points compared to base-line has been calculated using Mann-Whitney $U$ test. Correlation was calculated using Spearman's test. Significant levels were $* P<0.05$, $* * P<0.01$ and $* * * P<0.001$.

\section{Results}

During this study, the effect of strenuous physical exercise on circulation of various leukocytes and inflammatory markers, such as circulating cf-mtDNA and suPAR were measured.
Maximal heart rate of the participants was reached at individual time points ranging from 16.5 to $25.5 \mathrm{~min}$, with a median value of $20.5 \mathrm{~min}$ (Table 1).

\section{Circulating cell-free mtDNA (cf-mtDNA)}

The presence of cf-mtDNA in plasma increased in all participants during exercise. The kinetics for the presence of $\mathrm{cf}-$ mtDNA and cf-nDNA resp. indicate that the amount of cfmtDNA increased more during rest while cf-nDNA mainly increased closer to maximal workload (Table 2). However, a significant increase $(P<0.05)$ was only observed 30 and 90 min after maximal work-load. Although there was an individual difference of the absolute levels of cf-mtDNA units, the relative difference between time point $\mathrm{P}-0$ (before the exercise) and all other time points was substantial. Even after 90 min of rest from the physical test, the level was more than 25 times increased (Fig. 1a). The ratios between cf-mtDNA and cf-nDNA increase during and after exercise, however, not significantly, compared to baseline values (Fig. 1b).

\section{Circulating leukocytes}

The total number of blood leukocytes increased significantly $(P=0.0013)$ from $5.2 \times 10^{9} / \mathrm{L}$ to a maximal of $9.0 \times 10^{9} / \mathrm{L}$ during maximal workload but returned to baseline values after $90 \mathrm{~min}$ of rest (Fig. 2a). Circulating lymphocytes were significantly increased at maximal workload, compared to baseline, but returned to baseline after $30 \mathrm{~min}$ of rest. $90 \mathrm{~min}$ of rest resulted in a significant decrease of lymphocytes, compared to baseline (Fig. 2b). The number of circulating monocytes and neutrophils increased significantly from baseline until maximal workload was reached (data not shown).

The mean fluorescent intensity from CD87 on neutrophils showed a significant decrease during sub-maximal

Table 1 The primers (Life Technologies, Pailsey, UK) used for PCR amplification of cf-mtDNA and nDNA, respectively

\begin{tabular}{llll}
\hline Gene & Primer forward & Primer reverse & Access nr \\
\hline ND2 & CACACTCATCACAGCGCTAA & GGATTATGGATGCGGTTGCT & KJ676545 \\
$\beta 2 \mathrm{M}$ & TGTTCCTGCTGGGTAGCTCT & CCTCCATGATGCTGCTTACA & M17987 \\
\hline
\end{tabular}

Table 2 Amount of DNA during different time points of exercise. Results are given as mean values $\pm \mathrm{SD}$

\begin{tabular}{lllllr}
\hline DNA origin & P-0 & P-sub & P-max & P-30 & \multicolumn{1}{l}{ P-90 } \\
\hline cf-mtDNA, copies $/ \mathrm{L} \times 10^{6}$ & $22.2 \pm 26.3$ & $39.7 \pm 94.0$ & $26.5 \pm 21.0$ & $90.8 \pm 153.8$ & $228.9 \pm 483$ \\
cf-nDNA, copies $/ \mathrm{L} \times 10^{6}$ & $28.22 \pm 58.8$ & $15.8 \pm 29.7$ & $46.1 \pm 69.6$ & $49.6 \pm 50.6$ & $39.0 \pm 52.6$ \\
\hline
\end{tabular}


a

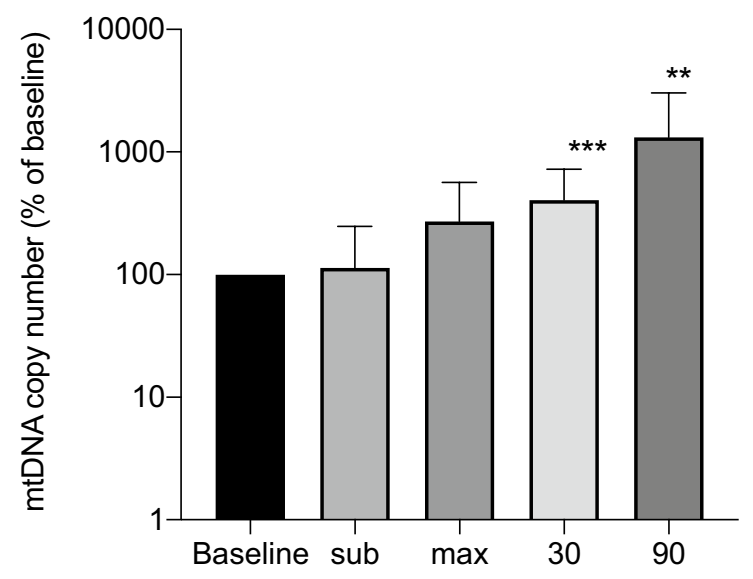

b

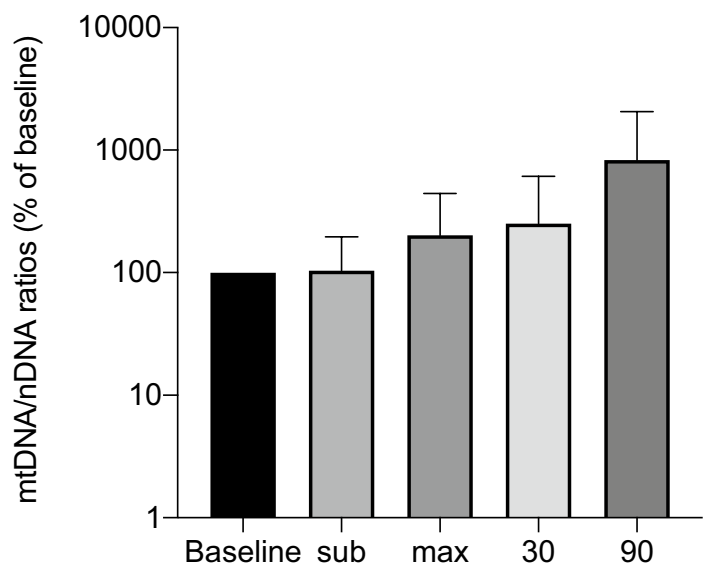

Fig. 1 Relative change of circulating cf-mtDNA compared to baseline at various time points during and after exercise (a) or relative change of rations between $\mathrm{mtDNA} / \mathrm{nDNA}$ compared to baseline (b)
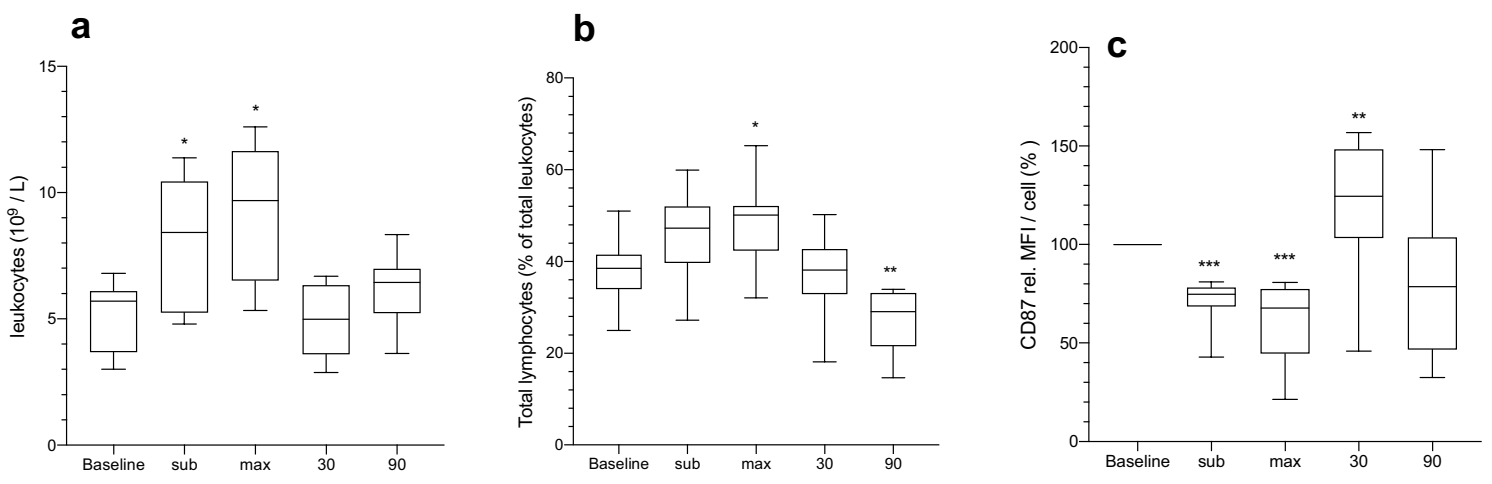

Fig. 2 Circulating leukocytes $\left(10^{9} / \mathrm{L}\right)$ in blood (a), total lymphocytes (\% of leukocytes) (b) and mean fluorescence intensity (MFI) from CD87 (\% of base-line) of neutrophils (c). ${ }^{*} P<0.05,{ }^{*} P<<0.01$ and $* * * P<0.001$ using Mann-Whitney $U$ test

and maximal work-load, but an increase after $30 \mathrm{~min}$ of rest (Fig. 2c).

\section{Concentration of plasma suPAR.}

The level of plasma suPAR was measured during all time points of the exercise showing a biphasic pattern. During the initial part of work-load, increased concentrations could be seen, however, after $30 \mathrm{~min}$ rest the concentration dropped but reached its highest concentration 90 min after maximal effort (Fig. 3a). Furthermore, the concentration of suPAR and MFI from CD87 on granulocytes showed an inversed relation, however, not significant $(P=0.0624)$ (Fig. 3b). No correlation between the levels of suPAR and the number of neutrophils was found.

\section{Discussion}

This study was performed to investigate if a single bout of strenuous physical exercise affects the concentration of cfmtDNA and suPAR in plasma. Furthermore, the concentration of total leukocytes was measured during the study, together with the presence of membrane-bound uPAR on the different leukocytes.

The results clearly show that the concentration of cfmtDNA was dynamically affected during the measurements. At sub-maximal and maximal work-load the concentration was mildly increased but a significant increase of concentrations could be seen after both 30 and 90 min of rest, compared to baseline levels. These results indicate that strenuous physical exercise induces some kind of cellular damage, leading to necrosis and the liberation of mitochondrial DNA. 
Fig. 3 Concentration of suPAR during all time points (a) and correlation between suPAR and MFI from CD87 (Spearman $r=-0.25)(\mathbf{b}) . * P<0.05$ using Mann-Whitney $U$ test
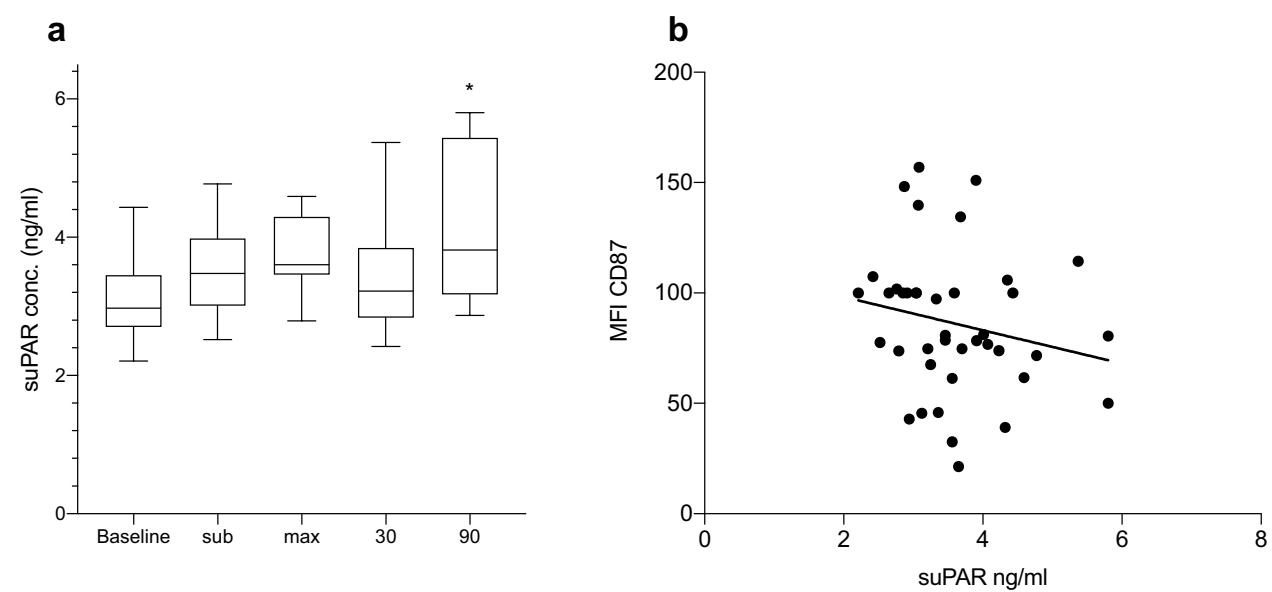

The results from the present study regarding cf-mtDNA differ from other studies showing decreased values of cfmtDNA (Beiter et al. 2011; Helmig et al. 2015). In one extensive study, repeated bouts of exhaustive exercise were carried out, giving rise to large increases of both cf-mtDNA but especially cf-nDNA (Stawski et al. 2017). A possible reason for the increased levels of cf-DNA, both nuclear- and mitochondrial origin, could be DNA liberation from neutrophils. Liberation of DNA from neutrophils, forming neutrophil-extracellular traps (NET) have been shown to take place rapidly after stimulation (Yousefi et al. 2009). Possible reasons for the contradicting results could be technical differences during sample treatment and DNA-isolation. Slightly different protocols are in use, with differences of centrifugation speed and time, among other things (Dantham et al. 2016; Kumar et al. 2017). A reason for the raised values of the ratios between cf-mtDNA and n-DNA could be the fact that the primers targeting b2M do not bind to shorter fragments of damaged nuclear DNA (Jiang and Lo 2016).

Previous studies have shown that tissue damage occurs during physical exercise (Zwetsloot et al. 2014). Muscle cells, heavily loaded during physical exercise, are richly equipped with mitochondria. Hypoxia and tissue damage, due to over-load, are likely causes for the liberation of cfmtDNA from these cells (Zhang et al. 2010a, b).

In a recent study also investigating the release of cfmtDNA, another more extended exercise regime was used. The time of a tread-mill run was set to $90 \mathrm{~min}$ but only $60 \%$ of $\mathrm{VO}_{2}$ was used. During this weaker bout of physical work, a decreased level of cf-mtDNA was registered (Shockett et al. 2016), indicating that different grades of physical labour have different effects. Short term hard labour probably causes tissue damages, reminding of trauma, while prolonged medium exercise causes an increase of circulating neutrophils, absorbing liberated cf-mtDNA, resulting in the observed decrease. The samples from the different participants of the present study showed a substantial individual variation. According to previous studies, the concentration of cf-mtDNA is influenced by several factors, such as age and health status (Pinti et al. 2014). The amount of cf-mtDNA has been reported to increase significantly after 50 years of age, however, with large individual differences. Age is an important parameter, probably due to a gradual decrease of muscle mass, leading to increased necrosis and liberation of endogenous substances, including mtDNA (Mikkelsen et al. 2013). Increased levels of cf-mtDNA in plasma could also be a result of decreased ability to clear it from the circulation (Kung et al. 2012). The mechanisms of clearing of cf-mtDNA have been discussed and studied by others and circulating neutrophils have been suggested to bind cf-mtDNA to TLR's acting as a sink (Shockett et al. 2016). Another theory is that increase of plasma DNase I activity, measured directly after exhaustive short-term exercise, could help restoring levels to base-line values (Beiter et al. 2011). Recently, it was reported that a sequence of DNA, targeted by the primers for the ND2-gene in the mitochondrial genome, is present on chromosome 1 in the human nuclear genome (NCBI Gene ID: 100652939). However, during our previous study of cf mtDNA, another primer-pair, targeting the ND1 gene in the mitochondrial genome, both pairs of primers were found to correlate to a high degree (Lindqvist et al. 2018).

An increased level of suPAR could be seen, during the exercise and the following rest, however, suPAR levels were only significantly raised $90 \mathrm{~min}$ after maximal work-load (Fig. 3a). Plasma concentrations of less than $4 \mathrm{ng} / \mathrm{mL}$ are considered as normal, while levels above $6 \mathrm{ng} / \mathrm{mL}$ may indicate illnesses such as cancer, diabetes or cardiovascular disease (Eugen-Olsen et al. 2010; Gustafsson et al. 2017; Kofoed et al. 2008). The cell-surface expression of the membrane-bound variant, uPAR, on the neutrophils was decreased during the same time, giving an almost inverted expression pattern, compared to suPAR (Fig. 3b). The negative correlation, although not 
significant, between suPAR and cell-surface expression of uPAR, measured as mean-fluorescent intensity (MFI) on granulocytes, supports the results of the study. The changes of suPAR-expression seen in this study are similar as during a study performed on patients suffering from major depressive disorder (MDD) (Gustafsson et al. 2017). An almost identical pattern of plasma-suPAR was found during that study, indicating that a single bout of strenuous physical exercise has a substantial effect on suPAR levels. The rather immediate increase of suPAR and decrease of uPAR fits well with the theory that UPAR is cleaved by a mixture of activated proteases and acute-phase proteins (Thuno et al. 2009). The concentration of suPAR measured by Sanchis-Gomar et al. (2014) before and after a football match was not reported to change, however, the subjects were all athletes, probably accustomed to physical exercise. The blood samples after the match were, however, taken $12 \mathrm{~h}$ after the match was finished. In a recent study, including 80 participants and 53 controls, it was reported that mild physical training, during a five-month period of time, did not have any effect on suPAR-levels (Rohde et al. 2018). On the other hand, a healthy lifestyle has been shown to significantly affect the levels of suPAR (Haupt et al. 2019) with higher concentrations measured in smokers and physically inactive participants. One interpretation of the different results is that suPAR levels indicate an acute inflammatory response, as mimicked during heavy physical exercise, but also a low-grade on-going inflammation, manifested as a result of unhealthy and sedentary lifestyle.

The expression of uPAR has been found on several blood leukocytes, including granulocytes, monocytes and activated T-lymphocytes (Koch et al. 2014; Thuno et al. 2009). The leukocytosis, resulting from de-margination of cells during heavy exercise, probably contributes to the increase of suPAR, since the levels of suPAR and total leukocytes have a similar concentration profile. Another explanation to the increase of suPAR could be a possible microbial translocation across the gut, resulting in the occurence of lipopolysaccharide (LPS) (Brenchley et al. 2006; Ng et al. 2008) in connection with physical exercise.

Several different proteases have been demonstrated to cleave UPAR in the linker region, including the urokinase plasminogen activator (uPA) itself, plasmin, chymotrypsin, and various MMPs (Andolfo et al. 2002). Increased plasma levels of uPA have previously been shown to result from physical exercise (Dooijewaard et al. 1991). When uPA is bound to UPAR, the receptor is cleaved, and suPAR, the soluble form of UPAR, is released. Since it has also been shown that heavy exercise can contribute to elevated levels of metalloprotease-9 (MMP-9) (Rullman et al. 2013), this protease could also be involved in the cleavage of UPAR leading to suPAR production.
One limitation of the study is the lack of blood-samples at later time-points. It would be interesting to measure the levels of both cf-mtDNA and suPAR during the following day and compare that to the leukocyte concentration.

A further limitation of the study is the low number of participants, making excessive conclusions from the results difficult. However, the aim of the study was reached, and was in line with the study by Stawski et al. (2017), encouraging further examinations of the effect from exercise on the immune response and the use of cf-mtDNA and suPAR in measurements. The increased levels of plasma IL-6, measured in connection to extensive exercise (Ullum et al. 1994), further strengthens the results indicating that exercise induces an inflammatory reaction manifested in several ways. Further studies will have to be performed to clarify the mechanisms involved.

Acknowledgements Open access funding provided by Malmö University.

Author contributions All authors contributed to the study conception and design. Material preparation, data collection and analysis were performed by all listed authors. The first draft of the manuscript was written by Lars Ohlsson and all authors commented on previous versions of the manuscript. All authors read and approved the final manuscript.

Funding This study was funded by Malmö University, Sweden.

Data availability The datasets generated during and/or analysed during the current study are available from the corresponding author on reasonable request.

\section{Compliance with ethical standards}

Conflict of interest The authors declare that they have no conflict of interest.

Ethical approval All procedures performed in studies involving human participants were in accordance with the ethical standards of the institutional research committee (The Ethical council at the department for Health and Society, Malmö University, Dnr: HS60-2015/306:2) and with the 1964 Helsinki declaration and its later amendments or comparable ethical standards.

Informed consent Informed consent was obtained from all individual participants included in the study.

Open Access This article is licensed under a Creative Commons Attribution 4.0 International License, which permits use, sharing, adaptation, distribution and reproduction in any medium or format, as long as you give appropriate credit to the original author(s) and the source, provide a link to the Creative Commons licence, and indicate if changes were made. The images or other third party material in this article are included in the article's Creative Commons licence, unless indicated otherwise in a credit line to the material. If material is not included in the article's Creative Commons licence and your intended use is not permitted by statutory regulation or exceeds the permitted use, you will need to obtain permission directly from the copyright holder. To view a copy of this licence, visit http://creativecommons.org/licenses/by/4.0/. 


\section{References}

Alis R, Sanchis-Gomar F, Primo-Carrau C, Lozano-Calve S, Dipalo M, Aloe R, Lippi G (2015) Hemoconcentration induced by exercise: revisiting the Dill and Costill equation. Scand J Med Sci Sports 25(6):e630-637. https://doi.org/10.1111/sms.12393

Andolfo A, English WR, Resnati M, Murphy G, Blasi F, Sidenius N (2002) Metalloproteases cleave the urokinase-type plasminogen activator receptor in the D1-D2 linker region and expose epitopes not present in the intact soluble receptor. Thromb Haemost 88(2):298-306

Beiter T, Fragasso A, Hudemann J, Niess AM, Simon P (2011) Short-term treadmill running as a model for studying cell-free DNA kinetics in vivo. Clin Chem 57(4):633-636. https://doi. org/10.1373/clinchem.2010.158030

Bhagirath VC, Dwivedi DJ, Liaw PC (2015) Comparison of the proinflammatory and procoagulant properties of nuclear, mitochondrial, and bacterial DNA. Shock 44(3):265-271. https://doi. org/10.1097/SHK.0000000000000397

Boettger S, Muller HJ, Oswald K, Puta C, Donath L, Gabriel HH, Bar KJ (2010) Inflammatory changes upon a single maximal exercise test in depressed patients and healthy controls. Prog Neuropsychopharmacol Biol Psychiatry 34(3):475-478. https://doi. org/10.1016/j.pnpbp.2010.01.016

Brenchley JM, Price DA, Schacker TW, Asher TE, Silvestri G, Rao S, Douek DC (2006) Microbial translocation is a cause of systemic immune activation in chronic HIV infection. Nat Med 12(12):1365-1371. https://doi.org/10.1038/nm1511

Castellano V, Patel DI, White LJ (2008) Cytokine responses to acute and chronic exercise in multiple sclerosis. J Appl Physiol 104(6):1697-1702. https://doi.org/10.1152/japplphysiol.00954 .2007

Chiu RW, Chan LY, Lam NY, Tsui NB, Ng EK, Rainer TH, Lo YM (2003) Quantitative analysis of circulating mitochondrial DNA in plasma. Clin Chem 49(5):719-726. Retrieved from https://www. ncbi.nlm.nih.gov/pubmed/12709361; https://clinchem.aaccjnls. org/content/clinchem/49/5/719.full.pdf

Dantham S, Srivastava AK, Gulati S, Rajeswari MR (2016) Plasma circulating cell-free mitochondrial DNA in the assessment of Friedreich's ataxia. J Neurol Sci 365:82-88. https://doi.org/10.1016/j. jns.2016.04.016

Dooijewaard G, Deboer A, Turion PNC, Cohen AF, Breimer DD, Kluft C (1991) Physical exercise induces enhancement of urokinasetype plasminogen-activator (U-Pa) levels in plasma. Throm Haemost 65(1):82-86

Enocsson H, Sjowall C, Wettero J (2015) Soluble urokinase plasminogen activator receptor - a valuable biomarker in systemic lupus erythematosus? Clin Chim Acta 444:234-241. https://doi. org/10.1016/j.cca.2015.02.031

Eugen-Olsen J, Andersen O, Linneberg A, Ladelund S, Hansen TW, Langkilde A, Haugaard SB (2010) Circulating soluble urokinase plasminogen activator receptor predicts cancer, cardiovascular disease, diabetes and mortality in the general population. J Intern Med 268(3):296-308. https://doi.org/10.111 1/j.1365-2796.2010.02252.x

Gustafsson A, Ventorp F, Wisen AG, Ohlsson L, Ljunggren L, Westrin A (2017) Effects of acute exercise on circulating soluble form of the urokinase receptor in patients with major depressive disorder. Biomark Insights 12:1-6. https://doi.org/10.1177/1177271917 704193

Hallberg L, Janelidze S, Engstrom G, Wisen AG, Westrin A, Brundin L (2010) Exercise-induced release of cytokines in patients with major depressive disorder. J Affect Disord 126(1-2):262-267. https://doi.org/10.1016/j.jad.2010.02.133
Haupt TH, Rasmussen LJH, Kallemose T, Ladelund S, Andersen O, Pisinger C, Eugen-Olsen J (2019) Healthy lifestyles reduce suPAR and mortality in a Danish general population study. Immun Ageing 16:1. https://doi.org/10.1186/s12979-018-0141-8

Helmig S, Fruhbeis C, Kramer-Albers EM, Simon P, Tug S (2015) Release of bulk cell free DNA during physical exercise occurs independent of extracellular vesicles. Eur J Appl Physiol 115(11):2271-2280. https://doi.org/10.1007/s00421-015-3207-8

Jiang P, Lo YMD (2016) The long and short of circulating cell-free DNA and the ins and outs of molecular diagnostics. Trends Genet 32(6):360-371. https://doi.org/10.1016/j.tig.2016.03.009

Johannsen DL, Ravussin E (2009) The role of mitochondria in health and disease. Curr Opin Pharmacol 9(6):780-786. https://doi. org/10.1016/j.coph.2009.09.002

Koch A, Zimmermann HW, Gassler N, Jochum C, Weiskirchen R, Bruensing J, Tacke F (2014) Clinical relevance and cellular source of elevated soluble urokinase plasminogen activator receptor (suPAR) in acute liver failure. Liver Int 34(9):1330-1339. https ://doi.org/10.1111/liv.12512

Kofoed K, Eugen-Olsen J, Petersen J, Larsen K, Andersen O (2008) Predicting mortality in patients with systemic inflammatory response syndrome: an evaluation of two prognostic models, two soluble receptors, and a macrophage migration inhibitory factor. Eur J Clin Microbiol Infect Dis 27(5):375-383. https://doi. org/10.1007/s10096-007-0447-5

Kumar M, Srivastava S, Singh SA, Das AK, Das GC, Dhar B, Mondal R (2017) Cell-free mitochondrial DNA copy number variation in head and neck squamous cell carcinoma: a study of non-invasive biomarker from Northeast India. Tumour Biol 39(10):1010428317736643. https://doi.org/10.1177/1010428317 736643

Kung CT, Hsiao SY, Tsai TC, Su CM, Chang WN, Huang CR, Lu CH (2012) Plasma nuclear and mitochondrial DNA levels as predictors of outcome in severe sepsis patients in the emergency room. J Transl Med 10:130. https://doi.org/10.1186/1479-5876-10-130

Lindqvist D, Fernstrom J, Grudet C, Ljunggren L, Traskman-Bendz L, Ohlsson L, Westrin A (2016) Increased plasma levels of circulating cell-free mitochondrial DNA in suicide attempters: associations with HPA-axis hyperactivity. Transl Psychiatry 6(12):e971. https://doi.org/10.1038/tp.2016.236

Lindqvist D, Wolkowitz OM, Picard M, Ohlsson L, Bersani FS, Fernstrom J, Mellon SH (2018) Circulating cell-free mitochondrial DNA, but not leukocyte mitochondrial DNA copy number, is elevated in major depressive disorder. Neuropsychopharmacology 43(7):1557-1564. https://doi.org/10.1038/s41386-017-0001-9

Mikkelsen UR, Couppe C, Karlsen A, Grosset JF, Schjerling P, Mackey AL, Kjaer M (2013) Life-long endurance exercise in humans: circulating levels of inflammatory markers and leg muscle size. Mech Ageing Dev 134(11-12):531-540. https://doi.org/10.1016/j. mad.2013.11.004

Ng QY, Lee KW, Byrne C, Ho TF, Lim CL (2008) Plasma endotoxin and immune responses during a $21-\mathrm{km}$ road race under a warm and humid environment. Ann Acad Med Singapore 37(4):307-314

Pedersen BK, Hoffman-Goetz L (2000) Exercise and the immune system: regulation, integration, and adaptation. Physiol Rev 80(3):1055-1081. https://doi.org/10.1152/physrev.2000.80.3.1055

Pinti M, Cevenini E, Nasi M, De Biasi S, Salvioli S, Monti D, Cossarizza A (2014) Circulating mitochondrial DNA increases with age and is a familiar trait: Implications for "inflamm-aging". Eur J Immunol 44(5):1552-1562. https://doi.org/10.1002/eji.201343921

Rohde C, Polcwiartek C, Andersen E, Vang T, Nielsen J (2018) Effect of a physical activity intervention on suPAR levels: a randomized controlled trial. J Sci Med Sport 21(3):286-290. https://doi. org/10.1016/j.jsams.2017.06.018 
Rullman E, Olsson K, Wagsater D, Gustafsson T (2013) Circulating MMP-9 during exercise in humans. Eur J Appl Physiol 113(5):1249-1255. https://doi.org/10.1007/s00421-012-2545-z

Sanchis-Gomar F, Bonaguri C, Pareja-Galeano H, Gomez-Cabrera MC, Candel J, Vina J, Lippi G (2013) Effects of acute exercise and allopurinol administration on soluble urokinase plasminogen activator receptor (suPAR). Clin Lab 59(1-2):207-210

Sanchis-Gomar F, Lippi G (2014) Physical activity—an important preanalytical variable. Biochem Med (Zagreb) 24(1):68-79. https:// doi.org/10.11613/BM.2014.009

Scheffler IE (2001) Mitochondria make a come back. Adv Drug Deliv Rev 49(1-2):3-26

Shockett PE, Khanal J, Sitaula A, Oglesby C, Meachum WA, Castracane VD, Kraemer RR (2016) Plasma cell-free mitochondrial DNA declines in response to prolonged moderate aerobic exercise. Physiol Rep 4(1):1. https://doi.org/10.14814/phy2.12672

Simpson RJ, Kunz H, Agha N, Graff R (2015) Exercise and the regulation of immune functions. Prog Mol Biol Transl Sci 135:355-380. https://doi.org/10.1016/bs.pmbts.2015.08.001

Stawski R, Walczak K, Kosielski P, Meissner P, Budlewski T, Padula G, Nowak D (2017) Repeated bouts of exhaustive exercise increase circulating cell free nuclear and mitochondrial DNA without development of tolerance in healthy men. PLoS ONE 12(5):e0178216. https://doi.org/10.1371/journal.pone.0178216

Steensberg A, van Hall G, Osada T, Sacchetti M, Saltin B, Klarlund Pedersen B (2000) Production of interleukin-6 in contracting human skeletal muscles can account for the exercise-induced increase in plasma interleukin-6. J Physiol 529(Pt 1):237-242

Suchanek O, Podrazil M, Fischerova B, Bocinska H, Budinsky V, Stejskal D, Kolar P (2010) Intensive physical activity increases peripheral blood dendritic cells. Cell Immunol 266(1):40-45. https://doi.org/10.1016/j.cellimm.2010.08.010

Thuno M, Macho B, Eugen-Olsen J (2009) suPAR: the molecular crystal ball. Dis Markers 27(3):157-172. https://doi.org/10.3233/ DMA-2009-0657
Ullum H, Haahr PM, Diamant M, Palmo J, Halkjaerkristensen J, Pedersen BK (1994) Bicycle exercise enhances plasma Il-6 but does not change Il-1-alpha, Il-1-beta, Il-6, or Tnf-alpha pre-messengerRNA in Bmnc. J Appl Physiol 77(1):93-97

Wust S, Drose S, Heidler J, Wittig I, Klockner I, Franko A, Braun T (2018) Metabolic maturation during muscle stem cell differentiation is achieved by miR-1/133a-mediated inhibition of the Dlk1Dio3 mega gene cluster. Cell Metab 27(5):1026-1039. https://doi. org/10.1016/j.cmet.2018.02.022

Yousefi S, Mihalache C, Kozlowski E, Schmid I, Simon HU (2009) Viable neutrophils release mitochondrial DNA to form neutrophil extracellular traps. Cell Death Differ 16(11):1438-1444. https:// doi.org/10.1038/cdd.2009.96

Yu M (2012) Circulating cell-free mitochondrial DNA as a novel cancer biomarker: opportunities and challenges. Mitochondrial DNA 23(5):329-332. https://doi.org/10.3109/19401736.2012.696625

Zhang Q, Itagaki K, Hauser CJ (2010a) Mitochondrial DNA is released by shock and activates neutrophils via p38 map kinase. Shock 34(1):55-59. https://doi.org/10.1097/SHK.0b013e3181cd8c08

Zhang Q, Raoof M, Chen Y, Sumi Y, Sursal T, Junger W, Hauser CJ (2010b) Circulating mitochondrial DAMPs cause inflammatory responses to injury. Nature 464(7285):104-107. https://doi. org/10.1038/nature 08780

Zwetsloot KA, John CS, Lawrence MM, Battista RA, Shanely RA (2014) High-intensity interval training induces a modest systemic inflammatory response in active, young men. J Inflamm Res 7:9-17. https://doi.org/10.2147/JIR.S54721

Publisher's Note Springer Nature remains neutral with regard to jurisdictional claims in published maps and institutional affiliations. 